\title{
TENSILE STRENGTH OF ROUND BAR A 6061 FRICTION WELD JOINT INFLUENCED BY CHANGES ROOM TEMPERATURE
}

\author{
Muhammad Ikram Kido ${ }^{1)}$, Sugiarto $^{2)}$, Djarot B. Darmadi ${ }^{3)}$ \\ ${ }^{1}$ Jurusan Teknik Mesin, Fakultas Teknik, Universitas Brawijaya Malang, \\ Jl. Mayjen Haryono 167, Malang 65145, Indonesia. \\ Email: ${ }^{1}$ Ikram.kido@gmail.com.
}

\begin{abstract}
Aluminum alloy is non-Ferro material that very difficult to amalgamate using fusion welding, so it requires friction method. Friction welding is process for connecting metals without melting (solid state process), Process merging between the rotating speeds of material forces cause heat friction and at somepoint can be able to melt the materials and melting process occurs. The study aim is to determine tensile strength results from friction weld joints due to changes in ambient temperature of room. Material test is Aluminum A6061. Friction welding uses a lathe with rotation speed of $1600 \mathrm{rpm}$. The length size of material is $80 \mathrm{~mm}$ and $120 \mathrm{~mm}$, diameter $15 \mathrm{~mm}$, Champer angle 15, 65 bar friction force for 60 seconds, final compressive force 375 bar for 60 seconds and variations in ambient temperature namely room temperature $\left(T_{0}\right), 125{ }^{\circ} \mathrm{C}, 150^{\circ} \mathrm{C}$. The A 6061 joint produces the highest tensile strength at temperature $150{ }^{\circ} \mathrm{C}(188 \mathrm{MPa})$.
\end{abstract}

Keywords : Friction Welding, Tensile Strength, and Aluminum A6061

\section{Pendahuluan}

Paduan aluminium A6061 adalah paduan aluminium yang mengandung paduan magnesium $(\mathrm{Mg})$ dan silikon $(\mathrm{Si})$. Jenis paduan aluminium ini ditemukan dalam berbagai aplikasi, khususnya pada bagian sambungan seperti pada komponen mesin, kapal laut, struktur pesawat terbang, kendaraan berat dan transportasi kereta api[1]. Hal ini karena sifatsifatnya yang memiliki kekuatan tarik sedang, kemampuan pembentukan yang baik, kemampuan las yang baik dan ketahanan korosi yang baik[2]. Dalam perancangan suatu struktur pada komponen mesin, sering kali diperlukan sebuah proses penyambungan misalnya dengan pengelasan. Pengelasan merupakan kegiatan penyambungan dua buah logam dengan memanfaatkan sumber energi panas seperti energi gesekan, energi impuls, dan lain-lain [2]. Berbagai Metode dalam proses pengelasan diantaranya pengelasan fusi dan pengelasan gesek (friction welding) [4]. Proses pengelasan fusi biasanya masih sering dilakukan pada komponen mesin, hanya saja kekurangan dari las fusi sulit diterapkan pada paduan aluminium, karena cenderung menghasilkan cacat porositas dan retak selama solidifikasi [5]. Sehingga pengelasan gesek (Friction welding) menjadi solusi untuk memecahkan permasalahan penyambungan logam yang sulit dilakukan dengan pengelasan cair (fusion welding) karena suhu proses tetap dibawah titik lebur,bahan yang dilas, (solid state process), maka tidak memerlukan logam pengisi (filler metal), flux dan gas pelindung[6][7]. Sedangkan parameter proses yang penting dalam las gesek adalah waktu gesekan, tekanan gesekan, waktu tempa, kecepatan putar dan parameter lainnya adalah geometri permukaan kontak, diameter permukaan kontak dan kekasaran permukaan kontak. [7][2].

Irawan Y.S dkk, melakukan penelitian mengenai kekuatan puntir pada pengelasan gesek AA6061 yang dipengaruhi waktu gesek, tekanan tempa dan champer satu sisi pengaruh, hasil yang diperoleh rasio yang lebih kecil dari diameter area gesekan dan diameter spesimen (D1 / D2) dan waktu gesekan yang lebih pendek menghasilkan kekuatan torsi yang 
lebih tinggi dari sambungan las gesek pada gaya upset rendah, namun gaya tekan akhir yang tinggi memberikan efek yang lebih besar dalam meningkatkan kekuatan torsi sambungan las gesek dan mengurangi efek geometri kerucut satu sisi karena waktu gesekan yang lebih lama[2]. Selanjutnya Irawan Y.S dkk, meneliti tentang pengaruh kekasaran permukaan dan sudut champer pada pengelasan gesek continuos drive aluminium AA 6061, hasil yang didapatkan adalah semakin kecilnya kekasaran permukaan dan semakin kecilnya sudut champer akan menghasilkan kekuatan tarik yang tinggi dan persentase porositas yang minimum, karena area panas (heat input) yang dihasilkan kecil[8]. M. Abdullah F.A dkk, meneliti tentang pengaruh tekanan tempa (upset force) dan waktu penahan (holding time) pada pengelasan Alumunium 6061 dimana hasil yang didapatkan yaitu kekuatan tarik maksimum dari A 6061 sambungan CFDW ditemukan di spesimen dengan tekanan tempa (Upset Force) yakni 120 mpa dan waktu penahanan (Holding Time) yakni 20 detik[9]. Selanjutnya Andrzej Ambroziak, melakukan pengelasan gesek aluminium dengan aluminium paduan dan hasilnya adalah waktu yang lama dapat menyebabkan pembentukan fase intermetalik yang cenderung menyebabkan kerapuhan sambungan [10]. Dari beberapa penelitian sebelumnya, belum ada penelitian yang mengetahui pengaruh dari perbedaan temperatur ruang (Lingkungan) dalam pengelasan gesek aluminium paduan A 6061 terhadap kekuatan tarik sehingga hal tersebut menarik untuk dikaji.

\section{Metodologi Penelitian}

Untuk memudahkan dalam penelitian, maka dibuatlah diagram alir penelitian seperti gambar 1.

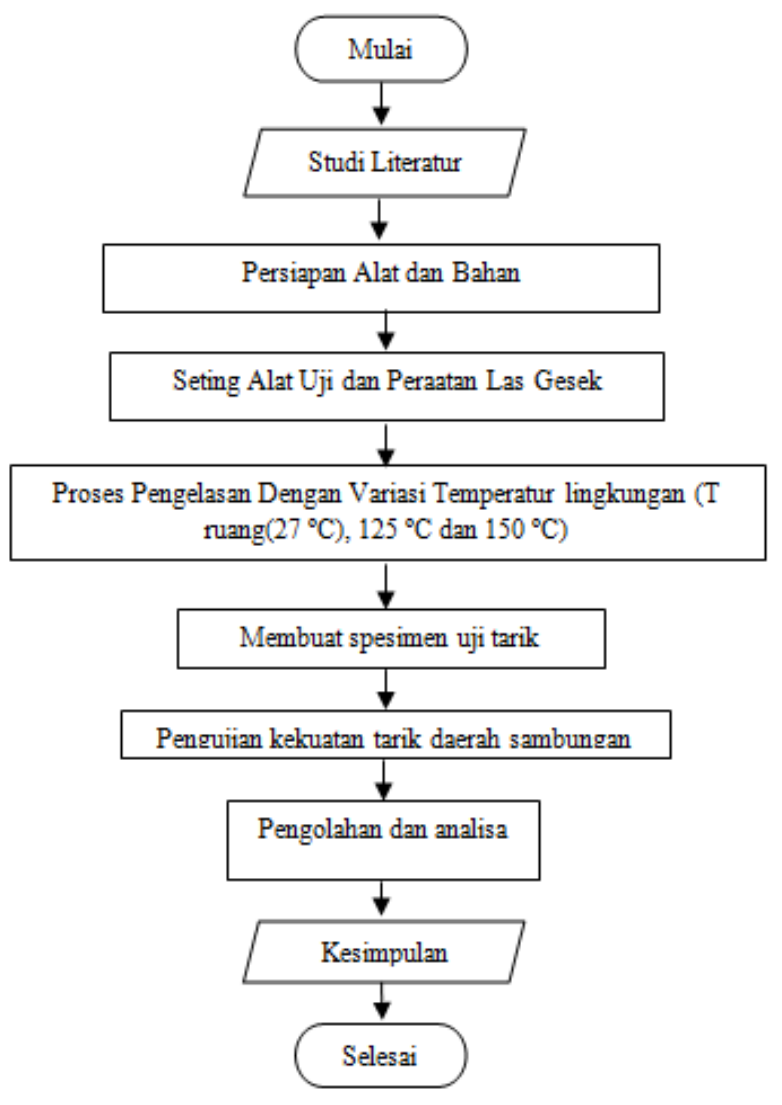

Gambar 1. Diagram Alir Penelitian

\subsection{Pengujian Komposisi Kimia}

Pengujian Komposisi kimia Aluminium A 6061 menggunakan peralatan uji XRF (XRay Floresence). Paduan Aluminium A 6061 memiliki paduan utama Aluminum, magnesium 
dan silikon. Tabel 1 menunjukkan komposisi kimia A6061 yang digunakan dalam penelitian ini.

Tabel. 1 Komposisi Kimia dari Aluminium A6061 (\% berat)

Sumber: Laboratorium Sentral Universitas Negeri Malang

\begin{tabular}{|lll|lll|}
\hline $\mathrm{Al}$ & $96.3 \%$ & $\mathrm{Zn}$ & $0.173 \%$ \\
\hline $\mathrm{Mg}$ & $0.71 \%$ & $\mathrm{Ni}$ & 0.02 & $\%$ \\
\hline $\mathrm{Si}$ & $0.51 \%$ & $\mathrm{Ti}$ & 0.090 & $\%$ \\
\hline $\mathrm{Fe}$ & $0.25 \%$ & $\mathrm{Ga}$ & $0.050 \%$ \\
\hline $\mathrm{Mn}$ & $0.15 \%$ & $\mathrm{Ba}$ & $0.03 \%$ \\
\hline $\mathrm{Cr}$ & $0.213 \%$ & $\mathrm{Yb}$ & $0.05 \%$ \\
\hline
\end{tabular}

\subsection{Energi termal yang dibangkitkan pada proses penggesekan}

Besarnya masukan panas (q) pada las gesek sangat dipengaruhi oleh luas kontak antar permukaan $(\Omega a)$, radius penampang melintang benda kerja $(r)$, kecepatan putaran $(\omega)$, tekanan benda kerja satu relative terhadap benda kerja yang berputar $(\mathrm{P})$, koefisien gesek dari material $(\mu)$ dan temperature $(\mathrm{T})$. Besarnya masukan panas tersebut dirumuskan oleh sebagai berikut:

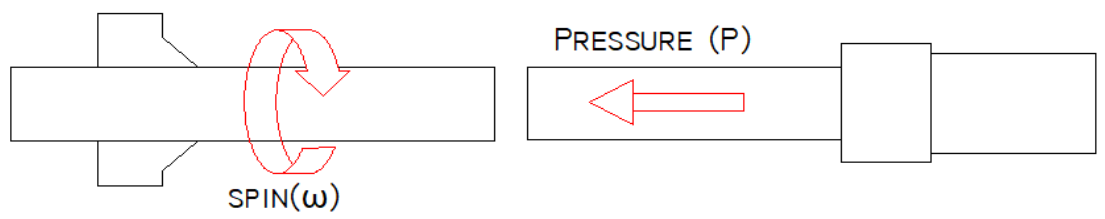

Gambar 2. Model skematis pada proses friction welding.

Sumber: Shubhavardhan, 2012, Hal.203

$\mathrm{E}=\mathrm{E} 1+\mathrm{E} 2$

E1 = Energi untuk menaikkan temperatur menuju ke temperatur mendekati cair (Solid state)

E2 = Energi yang dibutuhkan untuk terjadinya pelunakan atau energi yang dihasilkan dari proses mekanik (Torsi)

Temperatur pemanasan interface dua komponen dapat didekati dengan persamaan [10]:

$\mathrm{E}_{1}{ }^{\prime}=\mathrm{mcp} \Delta \mathrm{T}$

$\mathrm{E}_{1}{ }^{\prime}=\mathrm{mcp}\left(T_{1}-T_{0}\right)$

Dimana: $\mathrm{E}_{1}$ '= energi panas $(\mathrm{J})$

$\mathrm{m}=$ Massa yang akan dipanaskan $(\mathrm{kg})$

$\mathrm{cp} \quad=$ Panas spesifik material $\left(\mathrm{J} / \mathrm{Kg} .{ }^{\circ} \mathrm{K}\right)$

$T_{1}=$ Temperatur yang dihasilkan dari gesek $\left({ }^{\circ} \mathrm{K}\right)$

$T_{0} \quad=$ Temperatur ruang $\left({ }^{\circ} \mathrm{K}\right)$

Dan

$\mathrm{E}_{2}{ }^{\prime}=\mathrm{m} \mathrm{L}$

Dimana : $\mathrm{E}_{2}$ '= energi untuk perubahan fase dari padat ke cair yang besarnya sebanding dengan Tekanan dikali dL

$\mathrm{m} \quad=$ massa yang akan dipanaskan $(\mathrm{kg})$

$\mathrm{L}=$ kalor laten 


\subsection{Pembuatan Bahan Uji}

Pembuatan Bahan dilakukan di Laboratorium Proses Produksi Jurusan Teknik Mesin Universitas Brawijaya. Bahan uji aluminium A 6061 dipotong menggunakan mesin gergaji (hacksaw) dengan media pendingin air sebagai pendingin untuk menyiapkan spesimen. Kemudian dimensi bahan diproses dalam pengerjaan menggunakan mesin bubut, pada diameter $\varnothing 15 \mathrm{~mm}$, panjang $80 \mathrm{~mm}$ dan $120 \mathrm{~mm}$ dengan sudut champer $15^{\circ}$ kedua sisi permukaan ,bentuk bahan uji seperti pada Gambar 1.

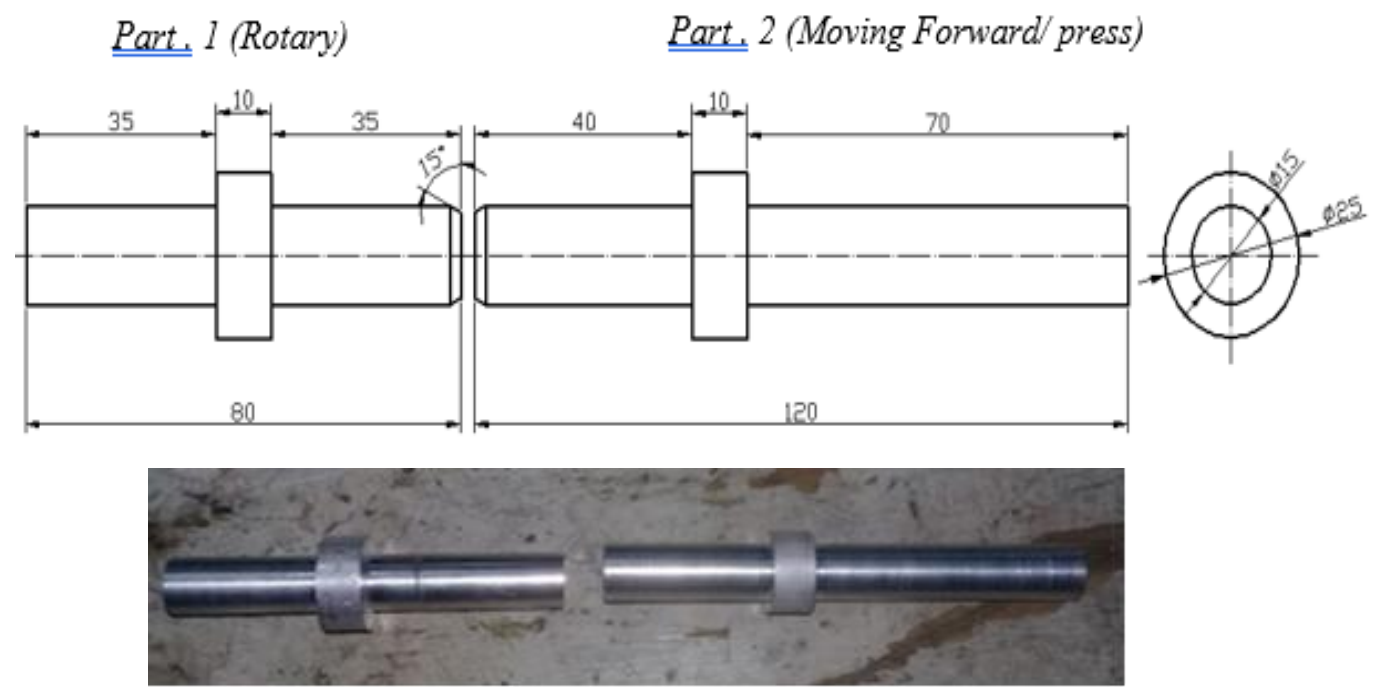

Gambar 3. Dimensi Benda Uji Aluminium A 6061

(Sumber : Laboratorium Proses Produksi Jurusan Teknik Mesin Universitas Brawijaya)

\subsection{Mesin Las gesek dan Alat Kontrol Temperatur Ruang}

Mesin las gesek yang digunakan merupakan mesin bubut (Gambar 2). Dengan parameter gesekan yakni Kecepatan Putaran 1600 rpm, tekanan gesek 65 bar selama 6 detik, gaya tekan akhir 375 bar selama 60 detik dan variasi temperatur lingkungan yakni temperatur ruang $\left(27^{\circ} \mathrm{C}\right), 125^{\circ} \mathrm{C}, 150^{\circ} \mathrm{C}$ dengan Alat Pemanas Udara (Heater)

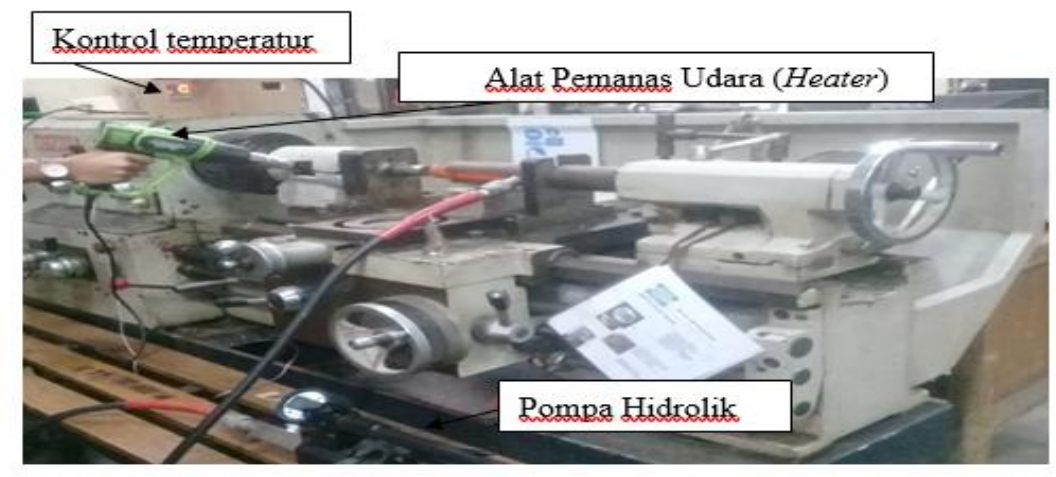

Gambar 4. Mesin Las Gesek (Mesin Bubut)

(Sumber: Laboratorium Proses Produksi Universitas Brawijaya)

Dalam proses friction welding, bagian spesimen yang berputar diatur dalam chuck pada headstock mesin bubut . Bagian stasioner dari spesimen dipasang pada tailstock mesin bubut yang terhubung ke silinder hidrolik dengan kapasitas 700 bar. Sebelum memulai proses pengelasan gesek, kedua permukaan gesekan dibersihkan menggunakan cairan aseton. Kecepatan rotasi spesimen yang diputar adalah $1600 \mathrm{rpm}$, kemudian mengatur temperatur 
lingkungan yang divariasikan (Truang $\left(\mathrm{T}_{0}\right)=27{ }^{\circ} \mathrm{C}, 125^{\circ} \mathrm{C}$ dan $150{ }^{\circ} \mathrm{C}$ ) pada alat kontrol temperatur, kemudian bagian stasioner spesimen bergerak ke spesimen yang berputar dengan menerapkan gaya tekan 65 bar untuk waktu gesekan 6 detik. Setelah waktu gesekan dan suhu tercapai, mesin bubut dimatikan dan spesimen menghasilkan flash, dilanjutkan untuk menahan gaya tekan akhir 375 bar selama 60 detik dan kemudian didinginkan di udara.

\subsection{Pengujian Las Gesek}

Pengujian yang dilakukan adalah pengujian tarik untuk mendapatkan kekuatan pada sambungan las gesek. Standar pengujian tarik menurut American Welding Standart (AWS) B4, 2016.

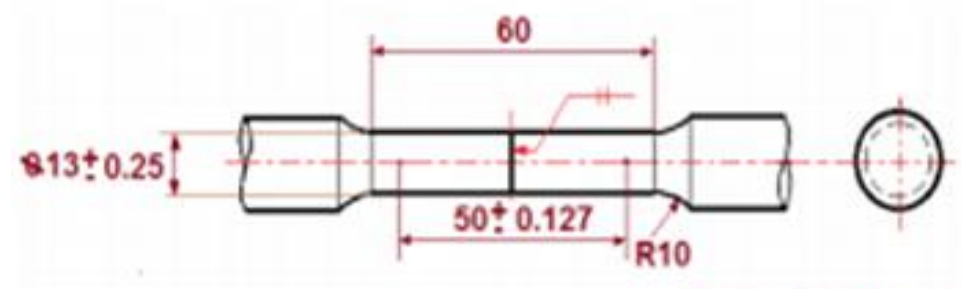

Satuan Dalam: mm

Gambar 5. Dimensi Standar Spesimen Uji Tarik

(Sumber. AWS B4, 2016, Hal.5)

\section{Hasil dan Pembahasan}

Berikut ini merupakan hasil pengujian tarik pada hasil lasan Aluminium A 6061 dengan variasi suhu yakni (suhu ruang yakni $27{ }^{\circ} \mathrm{C}$ tanpa perlakuan), $125{ }^{\circ} \mathrm{C}$ dan $150{ }^{\circ} \mathrm{C}$ (perlakuan dengan udara panas).

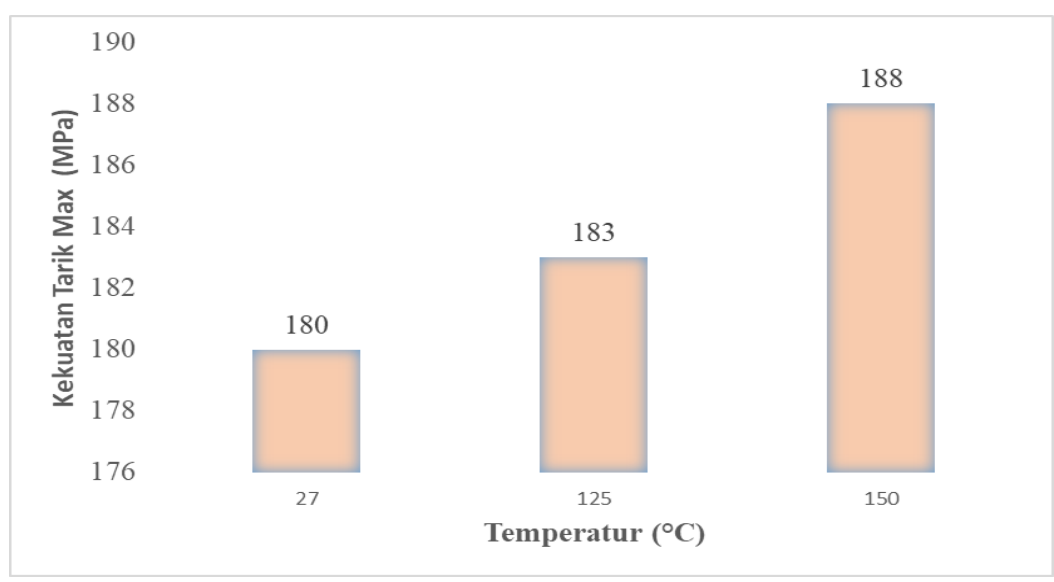

Gambar 6. Grafik Uji Tarik Aluminium A 6061

Dari Gambar 6. terlihat bahwa terjadi peningkatan nilai kekuatan tarik pada spesimen yang mengalami perlakuan dengan udara panas suhu $125^{\circ} \mathrm{C}$ dan $150^{\circ} \mathrm{C}$. Hasil yang diperoleh menunjukkan adanya gesekan pada pengelasan menimbulkan deformasi baik dan proses termal. Dengan adanya masukan panas yang cukup tinggi tetapi tidak terlalu tinggi menjamin plastisitas material, Jika material tidak cukup panas maka arus pelunakan tidak akan optimal sehingga dimungkinkan akan terjadi cacat rongga pada pengelasan.[11]

Selain itu sambungan las gesek juga menghasilkan patahan yang bentuknya mengalami pengecilan diameter $8 \mathrm{~mm}$ pada suhu $125^{\circ} \mathrm{C}$ dan $7 \mathrm{~mm}$ pada suhu $150{ }^{\circ} \mathrm{C}$. 
Sedangkan patahan temperatur ruang $\left(27^{\circ} \mathrm{C}\right)$ menghasilkan patahan dengan diameter lebih besar $(11 \mathrm{~mm})$ dari suhu $125^{\circ} \mathrm{C}$ dan $150^{\circ} \mathrm{C}$ seperti Gambar 5 dan Gambar 6 dibawah ini.

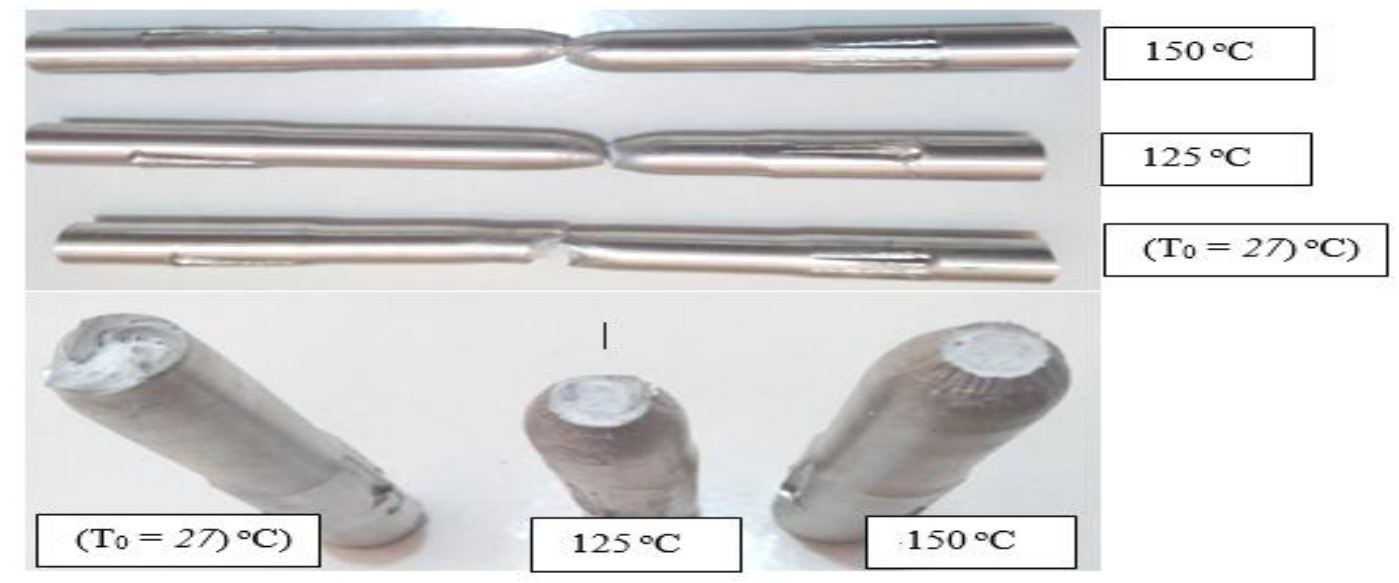

Gambar 7. Patahan Las gesek
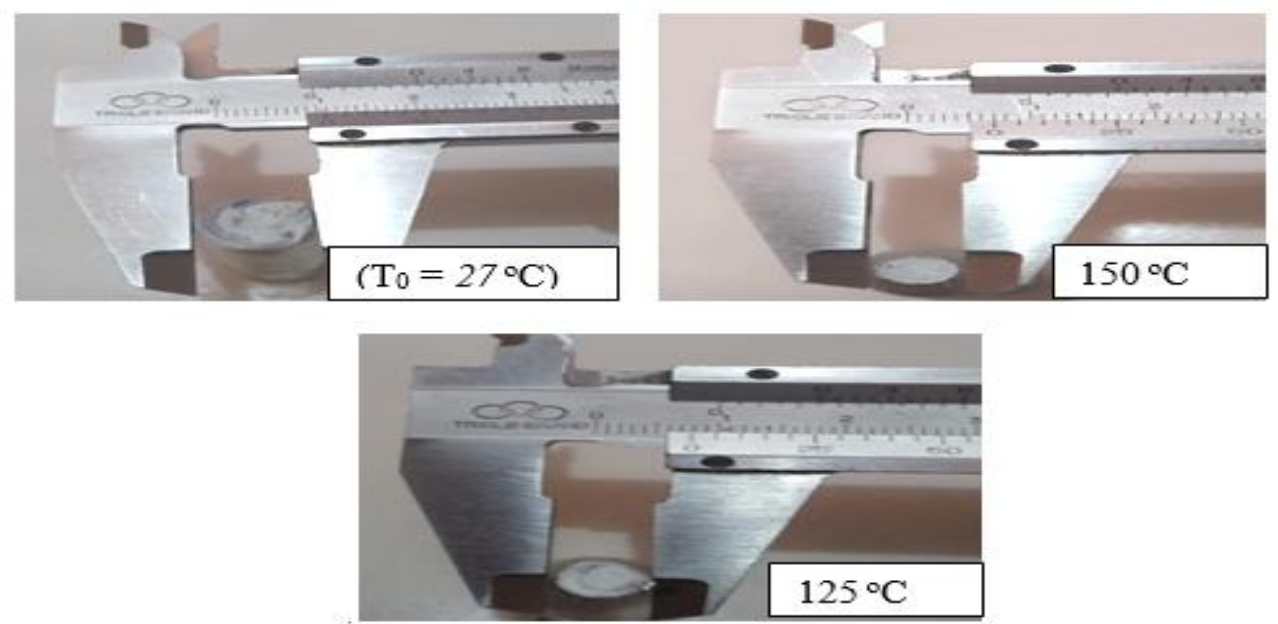

Gambar 8. Diameter Patahan Las gesek

Gambar 7 dan gambar 8 menghasilkan perpatahan ulet pada ketiga temperatur ( $\mathrm{T}$ ruang $\left(27^{\circ} \mathrm{C}\right)$ pada suhu $\left.125^{\circ} \mathrm{C}, 150{ }^{\circ} \mathrm{C}\right)$. Hal ini disebabkan akibat beban statis (tegangan geser) yang diberikan pada material, namun apabila beban dihilangkan maka perambatan retak akan berhenti. Tanda - tanda patah ulet yaitu penyerapan energi disertai dengan deformasi plastis yang cukup besar disekitar patahan, akibatnya permukaan patahan secara kasat mata terlihat kasar, berbentuk serabut (fibrous), dan berwarna kelabu. Selain dari pengaruh pembebanan, pengaruh komposisi kimia material juga sangat berpengaruh terhadap bentuk patahan dan jenis patahannya [12].

Selain itu menurut [12][13] patah ulet juga memiliki ciri- ciri pada patahannya membentuk sudut $45^{\circ}$ terhadap sumbu normal karena pengaruh tegangan geser yang maksimum atau dalam hal ini beban tarik yang bekerja menimbulkan tegangan sampai melebihi batas tegangan luluhnya, akibatnya pergerakan dislokasi hingga mencapai permukaan. Pergerakan dislokasi pada permukaan inilah yang dinamakan dengan deformasi plastis. Deformasi plastis yang lama kelamaan menyebabkan pertambahan panjang hingga spesimen bersifat tetap. Apabila besarnya tegangan diberikan lagi hingga mencapai titik Ultimate, maka spesimen mulai mengalami pengecilan setempat pada bagian tengahnya 
(necking). necking terjadi karena deformasi plastis yang terjadi pada material tidak lagi homogen.

\section{Kesimpulan}

Berdasarkan hasil penelitian dan pembahasan yang telah disajikan, kesimpulan yang diperoleh dari penelitian ini adalah (1) pengelasan gesek yang terjadi pada aluminium A 6061 menunjukkan perpatahan ulet. Hal ini ditunjukkan dengan pengecilan setempat pada bagian tengah spesimen atau mengalami fenomena necking. (2) perubahan temperatur ruang pada pengelasan gesek memberikan pengaruh hasil kekuatan tarik, dimana temperatur $150^{\circ} \mathrm{C}$ memberikan nilai kekuatan tarik yang tinggi yaitu $188 \mathrm{MPa}$.

\section{Ucapan Terimakasih}

Terima kasih kepada Pembimbing 1 yakni bapak Dr. Sugiarto, S.T, M.T dan pembimbimg 2 yakni bapak Ir. Djarot B Darmadi, Phd atas bimbingan dan arahannya kepada saya (mahasiswa).

\section{Daftar Pustaka}

[1] Bauccio, M. (Ed.). (1993). ASM metals reference book. ASM international.

[2] Irawan, Y. S., Suprapto, W., \& Oerbandono, T. (2017). Torsion Strength of Round Bar A6061 Friction Weld Joint Influenced by Friction Time, Upset Force and One-Side Cone Geometry. Journal of Environmental Engineering and Sustainable Technology, 4(2), 78-84.

[3] Taban, E., Gould, J. E., \& Lippold, J. C. (2010). Dissimilar friction welding of 6061-T6 aluminum and AISI 1018 steel: Properties and microstructural characterization. Materials \& Design (1980-2015), 31(5), 2305-2311.

[4] Pah, J. C. A., Irawan, Y. S., \& Suprapto, W. (2018). Pengaruh Waktu dan Tekanan Gesek terhadap Kekuatan Tarik Sambungan Paduan Aluminium dan Baja Karbon pada Pengelasan Gesek Continuous Drive. Rekayasa Mesin, 9(1), 51-59.

[5] Biradar, N. S., \& Raman, R. (2012). Investigation of hot cracking behavior in transverse mechanically arc oscillated autogenous AA2014 T6 TIG welds. Metallurgical and Materials Transactions A, 43(9), 3179-3191.

[6] James, J. A., \& Sudhish, R. (2016). Study on Effect of Interlayer in Friction Welding for Dissimilar Steels: SS 304 and AISI 1040. Procedia Technology, 25, 1191-1198.

[7] Shubhavardhan, R. N., \& Surendran, S. (2012). Friction welding to join dissimilar metals. International journal of emerging technology and advanced engineering, 2(7), 200-210.

[8] Irawan, Y. S., Imawan, B., Soenoko, R., \& Purnomo, H. (2016). Effect of surface roughness and chamfer angle on tensile strength of round aluminum A6061 produced by continuous drive friction welding. Journal of Engineering and Applied Sciences, 11(6), 1178-1185.

[9] Abdulla, F. A. M., Irawan, Y. S., \& Darmadi, D. B. (2018). Tensile Strength and Macro-microstructures of A6061 CDFW Weld Joint Influenced by Pressure and Holding Time in the Upset Stage. Rekayasa Mesin, 9(2), 149-154.

[10] Ambroziak, A., Korzeniowski, M., Kustroń, P., Winnicki, M., Sokołowski, P., \& Harapińska, E. (2014). Friction welding of aluminium and aluminium alloys with steel. Advances in Materials Science and Engineering, 2014.

[11] Tiwan, Aan Ardian. (2005). Penyambungan Baja Aisi 1040 Batang Silinder Pejal Dengan Friction Welding. Fakultas Teknik Universitas Negeri Yogyakarta

[12] Tarmizi, T., \& Prayoga, B. (2016). Analisa Sifat Mekanik dan Struktur Mikro pada Proses Friction Stir Welding Alumunium 5052. Jurnal Riset Teknologi Industri, 10(2), 
105-118.

[13] Callister, William D. (2013). Fundamentals Of Material Science and Engineering, 4th edition An Introduction. New York: John Wiley and Sons, Inc.

[14] Himawan, Citrakara Upendra S.B.K. (2016). Tensile Strength and Type of Fracture Differences On the Result Low carbon steel (ST 37) GMAW Welds due Normalizing process. Essay, Department of Mechanical Engineering, Faculty of Engineering, State University of Malang. 